\title{
Multi-Locus Genome-Wide Association Studies Reveal Novel Alleles for Flowering Time Under Vernalisation and Extended Photoperiod in a Barley MAGIC Population
}

\author{
Viet Hoang Dang \\ Murdoch University https://orcid.org/0000-0001-6408-6323 \\ Camilla Beate Hill \\ Murdoch University \\ Xiao-Qi Zhang \\ Murdoch University \\ Tefera Tolera Angessa \\ Murdoch University \\ Lee-Anne McFawn \\ Department of Primary Industries and Regional Development \\ Chengdao Li ( $\sim$ c.Li@murdoch.edu.au ) \\ Murdoch University https://orcid.org/0000-0002-9653-2700
}

\section{Research Article}

Keywords: multi-parental population, multi-locus GWAS, flowering time, pangenome, vernalisation, photoperiod

Posted Date: November 16th, 2021

DOI: https://doi.org/10.21203/rs.3.rs-1037957/v1

License: (c) (i) This work is licensed under a Creative Commons Attribution 4.0 International License. Read Full License 


\section{Abstract}

Optimal flowering time has a major impact on grain yield in crop species, including the globally important temperate cereal crop barley (Hordeum vulgare L.). Understanding the genetics of flowering is a key avenue to enhance yield potential. Bi-parental populations were used intensively to map genes controlling flowering. However, the lack of genetic diversity in bi-parental populations can lead to low mapping resolution and low allele richness, rendering the identification of underlying functional alleles difficult. Multiparent mapping populations such as nested association mapping (NAM) and multiparent advanced generation intercross (MAGIC) can overcome these limitations. The higher genetic and phenotypic diversity of multiple parents allows high-resolution quantitative trait loci (QTL) mapping. In this study, we use a MAGIC population from four commercial barley cultivars to identify genes controlling flowering time in different environmental conditions. Genome-wide association studies (GWAS) were performed using 5,112 high-quality markers from Diversity Arrays Technology sequencing (DArT-seq) and Kompetitive allele-specific polymerase chain reaction (KASP) genotyping. Phenotypic data was collected from 15 trials at different sites, across three consecutive years, various sowing times with/without vernalisation and extended photoperiod. This study detected 14 stable regions associated with flowering time across multiple environments. Minor regions associated with flowering time in certain environmental conditions were also identified. GWAS combined with pangenome data highlighted the role of CEN gene in flowering and enabled the prediction of different $C E N$ alleles from parental lines. These associations provide opportunities to utilise specific genes/alleles to create barley varieties with better grain yield and adaptation to growing conditions.

\section{Key Message}

Using a barley MAGIC population, key genes controlling flowering and interactions of different photoperiod alleles with various environments were identified. A new candidate gene for vernalisation requirements was also detected.

\section{Introduction}

Over the last 40 years, the development of new barley cultivars in combination with improved management practices has boosted the grain yield production rate in Australia to over 40 kilograms/ha each year (Anderson et al. 2005). With such improvements, barley grain yield in Australia had increased from 0.98 tons/ha in 1961 to 2.40 tons/ha in 2014. Despite these substantial gains, Australian barley yield still lags behind European countries such as Germany, which successfully increased their barley grain yield from 2 tons/ha in the early 19th century to a current level of more than 7 tons/ha (Friedt et al. 2011).

Optimal flowering time plays a significant role in grain yield improvement and has been targeted in many barley breeding programs. A later flowering time might provide plants with more extended growing periods, increasing the time to accumulate nutrients, and may result in a higher grain yield. It can also 
help plants to avoid frost damage, since the critical period of high frost sensitivity linked to spikelet survival and the number of grains per spike ranges from awn primordia development to heading (Alqudah and Schnurbusch 2014; Liu et al. 2020). However, later flowering can also increase the severeness of terminal heat and drought stress, which negatively impacts fertility and grain yield (Rana et al. 2017; Samarah 2005; Savin and Nicolas 1999). Moreover, water availability is crucial in maintaining barley yields, since water stress can significantly reduce the number of grain and grain weight, especially in many low rainfall growing regions (Samarah 2005; Savin and Nicolas 1999). Therefore, extending and matching the critical flowering period with optimal environmental conditions can help boost barley yield potential.

Many key genes and signalling pathways affecting flowering time as well as grain yield have been identified, and their interactions with the environment evaluated, particularly in model plants such as Arabidopsis and Oryza sativa (Colasanti and Coneva 2009; Fjellheim et al. 2014). In barley, the most significant pathways that affect flowering time are photoperiod (duration of exposure to light), vernalisation (prolonged exposure to low temperature) and earliness per se (influence the time of flowering independently of environmental stimuli) (Andres and Coupland 2012; Cockram et al. 2007).

In recent years, several studies have been conducted to detect Quantitative trait loci (QTLs) associated with flowering time in barley. Coventry et al. (2003) reported that Ppd-H1 and Earliness per se 2 (eps2) loci are related to grain size and grain weight performance in an Australian barley population. Cuesta-Marcos et al. (2009) suggested that there are five main QTLs, including Photoperiod 2 (Ppd-H2) and eps2 (or Early maturity 6, Eam6), that directly affect barley heading date and grain yield under autumn sowing conditions in Spain. Furthermore, Borràs-Gelonch et al. (2011) also reported that Ppd-H1 and Eam6 significantly affected flowering time in the Steptoe $x$ Morex population. A study by Alqudah et al. (2014) divided a mapping population based on photoperiodic response levels and suggested that $P p d-H 1, P p d-$ $\mathrm{H} 2$ and Constans 1 (CO1) genes play a major role in early heading under long-day conditions in barley. Another study conducted by Maurer et al. (2015) used nested association mapping (NAM) to detect eight major QTLs controlling flowering time in barley, with the major QTL effect corresponding to the photoperiod response gene Ppd-H1.

In the vernalisation pathway, the core gene Vernalisation 1 ( Vrn-H1), located on the long arm of chromosome $5 \mathrm{H}$, was reported to promote flowering following prolonged cold temperature (Cockram et al. 2007). The up-regulation of the $\mathrm{Vrn}-\mathrm{H} 1$ gene lead to the repression of the Vernalisation $2(\mathrm{Vrn}-\mathrm{H} 2)$ and consequently promoting the Flowering locus $T 1$ (FT1) gene (Sasani et al. 2009). A previous study reported that a deletion in the regulatory site of $\mathrm{Vrn}-\mathrm{H} 1$ combined with the deletion of $\mathrm{Vrn}-\mathrm{H} 2$ leads to a spring growth habit (Rollins et al. 2013). In spring barley, the combination of overexpression of Constans 2 (CO2) and a deletion in the $\mathrm{Vrn}-\mathrm{H} 2$ region leads to floral transition independent on $\mathrm{Ppd}-\mathrm{H} 1$ induction. In winter barley, the overexpression of $\mathrm{CO} 1$ or $\mathrm{CO} 2$ leads to the upregulation of $\mathrm{Vrn}-\mathrm{H} 2$, thus reduces the expression of $F T 1$, which results in a delay in flowering. 
Although many genes and QTLs associated with flowering have been reported, little information is available on functional alleles underlying these QTLs which are present in adapted domesticated lines. Crop populations derived from crosses of adapted domesticated cultivars enable the genetic dissection of complex traits while also providing allelic information of agronomically relevant cultivars, increasing the efficiency of subsequent breeding strategies. Multi-parent populations play a central role, as they combine many beneficial properties of genetic mapping populations by recombining the genomes of multiple parental varieties. In addition, multi-parent populations have high power and resolution for mapping quantitative trait loci, high genetic diversity and minimal population structure. These properties are important for the design of allele-specific markers for marker-assisted breeding (MAS) (Gupta et al. 2014; Myles et al. 2009).

In this study, a MAGIC population was constructed to take advantage of four commercial barley cultivars developed in different germplasm programs: Compass (Victoria, Australia), GrangeR (Europe), Lockyer (Western Australia) and La Trobe (South Australia). A total of 184 recombinant inbred lines (RILs) with maximum diversity in plant growth and phenology development were selected from the MAGIC population and sequenced using Diversity Array Technology (DArT) to obtain a total of 10,066 markers for GWAS. To provide additional coverage for the most important phenology and semi-dwarf genes as published previously in Dang et al. (2020); Hill et al. (2019a); Hill et al. (2021); Hill et al. (2019b) a total of 121 KASP markers, specifically targeting 66 key phenology genes, were also developed. To overcome the highly structured population and high linkage disequilibrium (LD), multi-locus GWAS methods were also used to provide an in-depth overview of the contribution of major phenology genes to phenology development, and to identify novel genes associated flowering time in barley.

The purpose of this study was to identify loci associated with flowering time under extended and natural light, as well as under vernalised and non-vernalised conditions with high resolution using a MAGIC population of 184 recombinant inbred lines (RILs). Beneficial parental alleles from these founders of the MAGIC population were identified for fine-tuning of flowering time in targeted growing conditions. To identify stable candidate genes controlling flowering time in various environmental conditions, trials in three consecutive years from 2017 to 2019 were set up in Perth, Western Australia. In addition, two more trials were conducted in Corrigin and Esperance, Western Australia in 2018. Different sowing times ranging from April to August were used to investigate the association of candidate genes with day-length and temperature on flowering time, which can be used as references for other growing sites with similar conditions across Australia. Vernalisation treatment and extended photoperiod conditions were used to identify genes responsible for controlling flowering under low temperature and prolonged day length.

\section{Material And Methods}

\section{Multi-parental population}

The MAGIC population were constructed using four commercial barley cultivars Compass, GrangeR, Lockyer, La Trobe and previously described in Dang et al. (2020). The parental cultivars were chosen 
based on their outstanding performance and exhibit high grain yield potential and grain yield stability in various production zones in Australia. Furthermore, these varieties represent germplasm pools from four major breeding programs, which are based in different locations across Australia and Europe, and were shown to contain high genetic variability in phenology genes.

These founders were crossed pairwise (Compass $\times$ GrangeR and Lockyer $\times$ La Trobe) to create two $F_{1}$ populations. The $F_{1}$ lines were then inter-crossed to generate 580 four-way

(Compass/GrangeR $\times$ Lockyer/La Trobe) $\mathrm{F}_{2}$ and $\sim 2000 \mathrm{~F}_{3}$ plants. The $\mathrm{F}_{3}$ population was advanced to the $F_{6}$ generation via single-seed descent (Brim 1966).

\section{Phenotypic data collection}

Phenotypic data was collected from 15 trials across Western Australia from 2017 to 2019 (Table S1). To investigate the seasonal impact, three trials were conducted in Perth, Western Australia, in three consecutive years from 2017 to 2019. The impact of different locations on flowering time was also assessed in two trials conducted in Corrigin and Esperance in 2018. To investigate the impact of different sowing times and vernalisation on flowering, ten trials with five different sowing dates spanned from April to August were conducted in Perth. Each sowing date included two trials: non-vernalised and vernalised. In the vernalisation experiments, seedlings were subjected to cold temperature at $4^{\circ} \mathrm{C}$ for $4-6$ weeks before transplanting to the field for phenology scoring. One extended photoperiod trial was also conducted in Perth with an 18-hour photoperiod.

Optimum management practices were applied for each trial, including weeding, disease control and fertilising based on local environmental conditions. Flowering time was as approximated using the awn appearance stage (Z49 based on the Zadoks' decimal scale) as described in Dang et al. (2020), Hill et al. (2021).

\section{Genotyping-by-sequencing by DArTseq and KASP assays}

To obtain high quality genotypic variants for association analysis, DNA samples from 184 selected RILs and four parental cultivars were sequenced using DArT to obtain a total of 10,066 high-quality singlenucleotide polymorphism (SNP) markers. DArT-Seq genotyping by sequencing (GBS) was performed using the DArT-Seq platform (DArT PL, Canberra, NSW, Australia) as described on the company website (https://www.diversityarrays.com). Briefly, $100 \mu \mathrm{l}$ of genetic material at $50 \mathrm{ng} / \mu \mathrm{L}$ was sent to DArT PL, and GBS was performed using a combination of complexity reduction followed by sequencing on a HiSeq Illumina platform (Illumina Inc., San Diego, CA, USA) as described by Akbari et al. (2006). Marker sequences were aligned against the Morex barley genome assembly (Mascher et al. 2017). The genetic position of each marker was determined based on the Morex physical reference assembly. 
To provide a better coverage of different haplotypes of the phenology genes, a total of $121 \mathrm{KASP}$ markers distributed over 66 phenology-related genes were also developed based on genetic information published for the four parental lines by Hill et al. (2019a), Hill et al. (2021), Hill et al. (2019b). These genes were previously reported to affect phenology, grain yield and plant height under different environmental conditions in Western Australia.

Genetic markers for KASP assays were designed based on the technology from LGC genomics (https://www.lgcgroup.com). KASP assays were conducted using $5 \mu$ reactions containing $50 \mathrm{ng}$ of highquality DNA template extracted from 3-week-old leaves, with annealing temperature reduced from $61^{\circ} \mathrm{C}$ to $57^{\circ} \mathrm{C}$ in the first ten cycles. The results were analysed using QuantStudio Real-Time PCR v1.3 software (Applied Biosystems, Australia).

\section{Genetic variant filtering and imputation}

The genotypic dataset was generated for 188 plant lines (186 selected RILs and four parental cultivars), containing a total of 10,066 SNP markers from DArT-seq, 121 KASP-based SNP markers covering major phenology genes, and three allele-specific markers for the semi-dwarf genes sdw1 and ari-e (Table S2). The data was converted to Variant Call Format (VCF v4.0) and filtered to remove variants with minor allele frequency (MAF) lower than $5 \%$ and missingness higher than $20 \%$ using PLINK 1.9 (Purcell et al. 2007). Genetic variants with heterozygous rates over $25 \%$ or showing no polymorphism among the four parental lines were also removed. The filtered marker set was imputed using BEAGLE 5.0 (Browning et al. 2018) and pruned using PLINK 1.9 (Purcell et al. 2007).

\section{Linkage disequilibrium and Population structure analysis}

Genome-wide LD analysis was performed using PLINK 1.9 (Purcell et al. 2007) with 5,112 filtered and imputed genetic markers for 184 RILs and four parental cultivars. LD was estimated by using squared allele frequency correlations $\left(r^{2}\right)$ between the intra-chromosomal pairs of loci (Weir, 1996). The loci were considered to be in significant LD when $\mathrm{P}<0.001$.

To investigate LD decay in the population, significant inter-chromosome $\mathrm{r}^{2}$ values within each $100-\mathrm{kb}$ bin were plotted against the physical distance $(\mathrm{kb})$ between markers. Curves were fitted by a second-degree LOESS function using R 3.6.1 (R Core Team 2013). Since the population is highly structured and not all genetic markers are informative, the marker set was further pruned based on the $r^{2}$ threshold of 0.8 using PLINK 1.9 (Purcell et al. 2007) and. The pruned dataset containing 2,207 genetic markers was used for population structure analysis and phylogenetic tree construction.

Population structure analysis was performed using Admixture 1.3.0 with different clusters (K) from 1 to 20 with 100 replications, and suitable $\mathrm{K}$ was selected based on cross-validation results (Alexander et al. 2009). The result was then collected, analysed and visualised using the R package "Pophelper 
2.3.1" (Francis 2017) and CLUMPP v1.1.2 (Jakobsson and Rosenberg 2007). A phylogenetic tree was constructed based on the distance matrix calculated as 1 - IBS (identity by state) similarity by TASSEL 5.0 (Bradbury et al. 2007) and visualised with FigTree 1.4 (Rambaut 2012).

\section{Genome-wide association analysis}

To investigate the vernalisation response, variation in flowering time between vernalised and nonvernalised were calculated using the following formula:

$$
Z 49_{\text {Variation }}=Z 49_{\text {Vernalised }}-Z 49_{\text {Non-vernalised }}
$$

Where Z49 Vernalised and Z49 Non-vernalised is define as flowering time of the same line growing under vernalisation treatment and under natural light conditions.

Genome-wide association analysis was performed using a total of 5,112 genetic variants present in 188 individual lines with different methods provided by the R packages "mrMLM v4.0.2". These methods including multi-locus random-SNP-effect mixed linear model (mrMLM), fast multiple-locus random-SNPeffect mixed linear model (FASTmrMLM), fast multi-locus random-SNP-effect efficient mixed-model association (FASTmrEMMA), least angle regression with empirical Bayes (pLARmEB), integrative sure independence screening expectation maximisation Bayesian least absolute shrinkage and selection operator model (ISIS EM-BLASSO) and Kruskal-Wallis test with empirical Bayes under polygenic background control (pKWmEB) (Zhang et al. 2020). The Q + K model was used, with the population structure matrix $\mathrm{Q}$ calculated by Admixture and the kinship matrix K calculated using the "mrMLM" packages. The default parameters were used, with the significance of Logarithm of Odds (LOD) of 3 to determine significant QTNs associated with flowering time, the search radius of candidate genes of $20 \mathrm{~kb}$ was used mrMLM and FASTmrEMMA and 50 potential association loci on each chromosome for pLARmEB (Zhang et al. 2020).

Linkage of markers identified by GWAS was visualised with Haploview (Barrett et al. 2004). Significan QTNs from GWAS results from multiple trials were collected and visualised using Circos 0.69 (Krzywinski et al. 2009).

\section{Pangenome sequence analysis}

The pan-genome data of the genome sequences from 20 different barley accessions were obtained from Leibniz Institute of Plant Genetics and Crop Plant Research (https://barley-pangenome.ipkgatersleben.de) (Jayakodi et al. 2020). The reference sequence of the CEN gene was obtained from the Morex genome sequence and blasted against the pan-genome dataset to identify the copy number as well as the physical position of the CEN gene on each of the accession sequences using "blastn" (Altschul 
et al. 1990). The $C E N$ gene from each pan-genome sequence was extracted, and multiple alignments were performed using Muscle 3.8.31 (Edgar 2004) to obtain genetic variants.

The phylogenetic tree was constructed using TASSEL 5 (Bradbury et al. 2007) with the high-quality SNP data of the CEN gene were obtained from the previous studies of Hill et al. (2019a), Hill et al. (2019b) and the SNP data derived from sequence alignment.

\section{Results}

\section{Impact of vernalisation treatment and extended photoperiod on flowering time}

Vernalisation treatment promoted flowering in all trials compared to non-vernalised plants (Fig. 1a-e). The impact of vernalisation was more significant for earlier sowing times, with an average of 21 and 13.3 days earlier in flowering when sowed in April and May, respectively (Table S3). However, vernalisation treatment showed minimal impact on plants sown in July and August, with the different in flowering time between vernalised and non-vernalised plants was only 3.4 and 1.2 days in July and August, respectively (Table S3). Plants grown under extended day length conditions exhibited earlier flowering habits, with an average of 33.7 days earlier in flowering compared to normal conditions (Fig. 1f and Table S3).

\section{Population structure and LD analysis}

Initial filtering with MAF and missingness resulted in the removal of 2,434 markers (23\%) from the dataset. Further filtering of the imputed dataset suggested no major changes after the imputation process, with all markers passing the filtering threshold. The minor allele frequency of the dataset before and after filtering and imputing is shown in Fig. S1ab. The filtered and imputed marker set were used for LD analysis. The LD analysis result suggested strong linkages between markers even at long distances of up to $10 \mathrm{Mb}$ (long-distance LD) (Fig. S1c).

The phylogenetic tree constructed from the neighbour-joining tree results calculated by TASSEL 5.0 (Bradbury et al. 2007) showed that the RILs had different genetic combinations of the four parental cultivars, with groups highly related to a single parental cultivar as well as groups sharing genetic combinations of multiple cultivars (Fig. S2).

The cross-validation (CV) result from population structure analysis showed that the average CV error dropped significantly from 0.989 to 0.869 when $\mathrm{K}$ increased from 1 to 6 . This value then decreased slightly to 0.822 at $K$ of 12 before increase slightly and dropped to the lowest value at $K$ of $15(0.817)$. Therefore, the population analysis result of $\mathrm{K}=12$ was collected using CLUMPP (Jakobsson and Rosenberg 2007) and visualised using the R package "Pophelper" (Francis 2017) (Fig. 2ab). The Q matrix from population analysis result of $\mathrm{K}=12$ was also used for later GWAS. 


\section{QTNs associated with flowering time}

A total of 154 significant QTNs associated with flowering time in different years, locations and sowing times were detected by GWAS (Table S4). Multiple QTNs can be linked to previously known regions such as D2H28394307_TC, D2H29454480_CT and D2H31462699_TG (located in the Ppd-H1 region). The Ppd$\mathrm{H} 1$ region also showed a strong association with flowering time in the extended photoperiod trial (Fig. 3q). Multiple QTNs, from D3H631680288_GC to D3H635379323_GC, are spanning GA20ox2 region. It is worth noting that the In-Del KASP marker designed explicitly for a mutation in the DEP1 gene (K5H482215793) was also associated with flowering in multiple trials. There are two significant QTNs on chromosome 7H, D7H37802896_AG and D7H40095600_TC, located in the region containing three genes previously reported to impact flowering: MADS-box 25-2 (MADS25-2), MADS-box 25-3 (MADS25-3) and FT1 (Fig. 3).

A region spanned from genetic marker D2H498405412_AG to genetic marker D2H585450069_GA (approximately $100 \mathrm{Mb}$ ) that showed significant association with flowering in most of the trials was also detected by GWAS. Linkage analysis suggested that these genetic markers are highly linked with LD scores ranged from 88 to 98 (Fig. S3).

A total of 42 significant SNPs were detected in the vernalisation trials with different sowing times from April to August in 2019 in Perth (Fig. 3l-p and Table S4). The Ppd-H1, GA20ox2 and FT1 regions still showed significant association with flowering time following vernalisation treatment. The linkage region spanned from genetic marker D2H498405412_AG to D2H592062371_GA also detected by GWAS in multiple vernalisation trials (Fig. 3l-p).

Further analysis from GWAS results showed that 14 stable regions were detected. These regions contained significant QTNs associating with flowering in two or more trials (Table 1). Besides major gene regions associated with flowering time in most of the trials (including Ppd-H1, GA20ox2, DEP1, CEN, FT1), there are several regions only showed association with flowering time in only 2 or 3 environments, such as PFT1 gene at $5 \mathrm{H}: 430868101$ and $1 \mathrm{H}: 4653106$ (Table 1).

Table 1 Stable regions associated with flowering time in at least two different trials 


\begin{tabular}{|c|c|c|c|c|}
\hline $\begin{array}{l}\text { Position/Inverval } \\
\text { (bp) }\end{array}$ & $\begin{array}{l}\text { Candidate } \\
\text { gene }\end{array}$ & $\begin{array}{l}\text { Haplotype } \\
1\end{array}$ & $\begin{array}{l}\text { Haplotype } \\
2\end{array}$ & Trial \\
\hline \multirow[t]{2}{*}{ 1H:4653106 } & & Compass & GrangeR & Esperance 2018 \\
\hline & & La Trobe & Lockyer & Corrigin 2018 \\
\hline $\begin{array}{l}2 \mathrm{H}: 28394307- \\
31462699\end{array}$ & Ppd-H1 & $\begin{array}{l}\text { Compass } \\
\text { GrangeR }\end{array}$ & $\begin{array}{l}\text { La Trobe } \\
\text { Lockyer }\end{array}$ & $\begin{array}{l}\text { Perth } 2017 \\
\text { Perth } 2018 \\
\text { Esperance } 2018 \\
\text { Corrigin } 2018 \\
\text { Perth April } 2019 \\
\text { Perth May } 2019 \\
\text { Perth August } 2019 \\
\text { Perth April } 2019 \text { Vernalised } \\
\text { Perth May } 2019 \text { Vernalised } \\
\text { Perth } 2019 \text { Extended photoperiod }\end{array}$ \\
\hline $\begin{array}{l}2 \mathrm{H}: 37222451- \\
38635094\end{array}$ & & $\begin{array}{l}\text { Compass } \\
\text { GrangeR }\end{array}$ & $\begin{array}{l}\text { La Trobe } \\
\text { Lockyer }\end{array}$ & $\begin{array}{l}\text { Perth } 2019 \text { August Vernalised } \\
\text { Perth } 2019 \text { Extended photoperiod }\end{array}$ \\
\hline $\begin{array}{l}\text { 2H:271995988- } \\
271999272\end{array}$ & & $\begin{array}{l}\text { Compass } \\
\text { La Trobe } \\
\text { Lockyer }\end{array}$ & GrangeR & $\begin{array}{l}\text { Perth } 2019 \text { July Vernalised } \\
\text { Esperance } 2018\end{array}$ \\
\hline $\begin{array}{l}2 \mathrm{H}: 402416491- \\
453687559\end{array}$ & & $\begin{array}{l}\text { Compass } \\
\text { La Trobe } \\
\text { Lockyer }\end{array}$ & GrangeR & $\begin{array}{l}\text { Perth } 2018 \\
\text { Perth April } 2019 \\
\text { Perth June } 2019 \\
\text { Perth August } 2019 \\
\text { Perth April } 2019 \text { Vernalised } \\
\text { Perth } 2019 \text { August Vernalised }\end{array}$ \\
\hline $\begin{array}{l}2 \mathrm{H}: 498405412- \\
585450069\end{array}$ & CEN & $\begin{array}{l}\text { Compass } \\
\text { La Trobe } \\
\text { Lockyer }\end{array}$ & GrangeR & $\begin{array}{l}\text { Perth } 2017 \\
\text { Perth } 2018 \\
\text { Corrigin } 2018 \\
\text { Esperance } 2018 \\
\text { Perth April } 2019 \\
\text { Perth May } 2019 \\
\text { Per June } 2019 \\
\text { Perth July } 2019 \\
\text { Perth August } 2019 \\
\text { Perth April } 2019 \text { Vernalised } \\
\text { Perth May 2019 Vernalised } \\
\text { Perth 2019 June Vernalised }\end{array}$ \\
\hline $\begin{array}{l}3 \mathrm{H}: 631680288- \\
635379323\end{array}$ & GA20ox2 & $\begin{array}{l}\text { Compass } \\
\text { La Trobe }\end{array}$ & $\begin{array}{l}\text { GrangeR } \\
\text { Lockyer }\end{array}$ & $\begin{array}{l}\text { Perth } 2017 \\
\text { Perth } 2018 \\
\text { Corrigin } 2018 \\
\text { Esperance } 2018 \\
\text { Perth April } 2019 \\
\text { Perth May } 2019 \\
\text { Per June } 2019 \\
\text { Perth April } 2019 \text { Vernalised } \\
\text { Perth May } 2019 \text { Vernalised }\end{array}$ \\
\hline $\begin{array}{l}5 \mathrm{H}: 39817622- \\
45772858\end{array}$ & & $\begin{array}{l}\text { Compass } \\
\text { GrangeR } \\
\text { Lockyer }\end{array}$ & La Trobe & $\begin{array}{l}\text { Perth } 2018 \\
\text { Perth July } 2019 \\
\text { Esperance } 2018\end{array}$ \\
\hline
\end{tabular}




\begin{tabular}{|c|c|c|c|}
\hline $\begin{array}{l}\text { 5H:382294832- } \\
390501082\end{array}$ & $\begin{array}{c}\text { Compass } \\
\text { GrangeR } \\
\text { Lockyer }\end{array}$ & La Trobe & $\begin{array}{l}\text { Perth May } 2019 \\
\text { Perth } 2019 \text { August Vernalised }\end{array}$ \\
\hline
\end{tabular}

\begin{tabular}{|c|c|c|c|c|}
\hline $5 \mathrm{H}: 430868101$ & PFT1 & Compass & $\begin{array}{l}\text { GrangeR } \\
\text { La Trobe } \\
\text { Lockyer }\end{array}$ & $\begin{array}{l}\text { Esperance } 2018 \\
\text { Corrigin } 2018\end{array}$ \\
\hline $\begin{array}{l}5 \mathrm{H}: 478394957- \\
482215793\end{array}$ & $D E P 1$ & $\begin{array}{l}\text { Compass } \\
\text { GrangeR } \\
\text { Lockyer }\end{array}$ & La Trobe & $\begin{array}{l}\text { Perth } 2018 \\
\text { Perth April } 2019 \\
\text { Perth May } 2019 \\
\text { Per June } 2019 \\
\text { Perth July } 2019 \\
\text { Perth } 2019 \text { June Vernalised }\end{array}$ \\
\hline $\begin{array}{l}5 \mathrm{H}: 562614128- \\
597950604\end{array}$ & $V r n-H 1$ & $\begin{array}{l}\text { Compass } \\
\text { La Trobe } \\
\text { Lockyer }\end{array}$ & GrangeR & $\begin{array}{l}\text { Esperance } 2018 \\
\text { Perth April } 2019 \\
\text { Perth August } 2019 \\
\text { Perth April } 2019 \text { Vernalised } \\
\text { Perth April } 2019 \text { Vernalised/Non- } \\
\text { Vernalised }\end{array}$ \\
\hline $\begin{array}{l}\text { 5H:628711504- } \\
651511097\end{array}$ & & $\begin{array}{l}\text { Compass } \\
\text { GrangeR } \\
\text { Lockyer }\end{array}$ & La Trobe & $\begin{array}{l}\text { Perth } 2018 \\
\text { Perth } 2019 \text { July Vernalised }\end{array}$ \\
\hline $\begin{array}{l}\text { 7H:37802896- } \\
40095600\end{array}$ & FT1 & $\begin{array}{l}\text { Compass } \\
\text { La Trobe }\end{array}$ & $\begin{array}{l}\text { GrangeR } \\
\text { Lockyer }\end{array}$ & $\begin{array}{l}\text { Corrigin } 2018 \\
\text { Esperance } 2018 \\
\text { Perth May } 2019 \\
\text { Per June } 2019 \\
\text { Perth August } 2019 \\
\text { Perth April } 2019 \text { Vernalised }\end{array}$ \\
\hline
\end{tabular}

Ppd-H1: Photopeiod 1, CEN: CENTRORADIALI, GA20ox2: Gibberellin 20 oxidase 2, PFT1: Phytochrome and Flowering time 1, DEP1: Dense and erect panicle 1, Vrn-1: Vernslisation 1, FT1: Flowering locus T 1.

\section{CENTRORADIALIS is the candidate gene for the high linkage region on chromosome $2 \mathrm{H}$}

A detailed investigation using the genetic markers spanned from D2H498405412_AG to D2H585450069_GA collected from GWAS showed that all the linked markers can be separated into two haplotypes, one inherited from cv. GrangeR and the other from cvs. Compass, La Trobe and Lockyer (Table S4).

Analysis of the D2H519658782_AC QTN located near the CEN region (523 Mb on chromosome $2 \mathrm{H}$ ) suggested that the GrangeR genotype (A genotype) showed a significant delay in flowering time in all trials (Fig. 4). The A genotype exhibited up to 12.2 days delay in flowering compared to the $\mathrm{C}$ genotype (Table S5). 
Analysis using 13 SNPs obtained from previous studies of Hill et al. (2019a), Hill et al. (2019b) and the pan-genome sequences of 20 barley accessions (Jayakodi et al. 2020) in the CENTRORADIALIS (CEM) gene region suggested that the $C E N$ sequence from $\mathrm{cv}$. GrangeR is similar to many well-known commercial cultivars such as Barke, RGT Planet and Golden Promise (Fig. 5a). It is worth noting that cvs. GrangeR, Barke, RGT Planet and Golden Promise carrying a C-to-A SNP in the last exon, which caused a change from Proline to Alanine in the translated protein (Fig. 5b). It is highly possible that the GrangeR genotype, carrying a C-to-A SNP in the last exon of the CEN gene, is responsible for the association of the linkage region on chromosome $2 \mathrm{H}$ with flowering time.

\section{The role of Ppd-H1 gene in photoperiod response}

The two genotypes of the D2H29454480_AC QTN, located near the Ppd-H1 gene region, showed significant differences in flowering time in multiple trials, including vernalised/non-vernalised and various locations. The A genotype of D2H29454480_AC QTN associated with later flowering time in Corrigin and Esperance and in early sowing dates in Perth (April and May) (Fig. 6 and Table S6). It is worth noting that the flowering time between the two genotypes groups sowing in June and July showed no significant difference $($ at $p$-value $=0.05)$.

While exhibited later flowering habits when sowed in April and May, the A genotype D2H29454480_AC QTN promoted flowering in August sowing time in Perth (non-vernalised) and extended light trials (Fig. 6). This might suggest that different alleles of the D2H29454480_AC QTN are associated with different Ppd$H 1$ alleles. However, plants following vernalisation treatment showed no significant difference in flowering time between the two genotype groups when sowed in August (Fig. 6e). Moreover, the $C$ genotype of D2H29454480_AC QTN showed a significant earlier in flowering time after vernalisation compared to the non-vernalised plants (Fig. 6f).

\section{Impact of the D2H638903073_TG QTN on vernalisation response}

Four significant QTNs were detected by GWAS using flowering time variation data calculated from vernalised and non-vernalised trials (Fig. 3r-v and Table S4). These four QTNs can be divided into two groups, one group spanning approximately $8 \mathrm{Mb}$ and located near the $\mathrm{Vrn}-\mathrm{H} 1$ gene region (D5H595203077_GA and D5H587440733_AG), the other group spanning an around $400 \mathrm{~kb}$ region on chromosome 2H (D2H638903073_TG and D2H639289577_GA).

Comparison of flowering time between vernalised and non-vernalised plants suggested that different genotypes of the D2H638903073_TG QTN showed different responses to vernalisation. In trials conducted in normal conditions, plants carrying the T genotype of the D2H638903073_TG QTN only showed significant differences (at p-value $=0.05$ ) in flowering time when comparing to the $\mathrm{G}$ genotype in the August sowing time (Table 2). However, the difference in flowering between the two genotype groups 
became more significant after vernalisation. Plants harbouring the T genotype of the D2H638903073_TG QTN exhibited significantly earlier flowering time than the $\mathrm{G}$ genotype in the vernalisation trials (Table 2). It is worth noting that the D2H638903073_TG QTN was not detected by GWAS using flowering time data in non-vernalised and vernalised trails (Fig. 3 and Table S4).

Table 2 Mean flowering time and standard error of different genotype of the D2H638903073_TG QTN in different sowing times and vernalisation trials in Perth, 2019

\begin{tabular}{lllllll} 
Sowing time & \multicolumn{2}{l}{ Non-vernalised } & \multicolumn{3}{l}{ Vernalised } \\
\cline { 2 - 3 } & \multicolumn{2}{l}{ Genotype } & & p-value & Genotype & \multirow{2}{*}{ p-value } \\
\cline { 2 - 3 } & T & G & & T & G & \\
\hline April 2019 & $89.4 \pm 0.8$ & $92.5 \pm 1.7$ & 0.114 & $68.2 \pm 0.8$ & $72.1 \pm 1.9$ & 0.068 \\
\hline May 2019 & $97.5 \pm 0.6$ & $98.2 \pm 1.2$ & 0.582 & $83.2 \pm 0.7$ & $87.8 \pm 1.6$ & $0.011^{*}$ \\
\hline June 2019 & $92.4 \pm 0.4$ & $94.6 \pm 1.3$ & 0.105 & $90.9 \pm 0.6$ & $94.4 \pm 1.3$ & $0.033^{*}$ \\
\hline July 2019 & $74.3 \pm 0.5$ & $76.2 \pm 0.9$ & 0.136 & $70.3 \pm 0.5$ & $74.5 \pm 0.7$ & $<0.001^{\star \star *}$ \\
\hline August 2019 & $65.7 \pm 0.4$ & $67.4 \pm 0.7$ & $0.038^{*}$ & $64.2 \pm 0.5$ & $67.5 \pm 0.9$ & $0.003^{\star \star}$
\end{tabular}

* $p$-value $<0.05, * \star p$-value $<0.01$, *** $p$-value $<0.001$.

\section{Discussion}

\section{Identification of QTN for flowering time using multi-locus GWAS approaches in a MAGIC population}

The identification of superior alleles is crucial for breeding of superior varieties in crops, including barley. In this study, we identified favourable alleles for flowering time by using the MAGIC population with Multilocus GWAS approaches. Multiple QTNs associated with flowering time were detected, especially on chromosomes $2 \mathrm{H}, 3 \mathrm{H}, 5 \mathrm{H}$ and $7 \mathrm{H}$ (Fig. 3). It is worth noting that these significant QTNs are inherited from different parental cultivars, which suggested that these cultivars carried different phenology genes/alleles (Table 1 and Table S4).

\section{Multiple sowing times, different locations, vernalisation treatment and extended photoperiod provided insights of genes responsible for environmental response}

The utilisation different environmental conditions played an important role in the detection of QTNs that respond to specific conditions. Although QTNs in the Ppd-H1 showed significant association with 
flowering time, especially in photoperiod response, their associations were not detected by GWAS in the June and July sowing time in Perth 2019. Genetic variations in the $P p d-H 1$ gene region was previously characterised by Turner et al. (2005). The photoperiod sensitive Ppd-H1 allele has been reported to promote flowering under long-day conditions (Acquaah 2012, Turner et al. 2005, Wiegmann et al. 2019). In this study, plants carrying the A genotype of D2H29454480_AC QTN promoted flowering in the extended photoperiod condition, which suggested that the A genotype is associated with the photoperiod sensitive allele of the $P p d-H 1$ gene. However, analysis using different sowing times and locations indicated that the A genotype exhibited late flowering habits when sowed in Esperance, Corrigin, April and May in Perth. The same genotype (A genotype) showed association with earlier flowering in the August sowing time in Perth 2019 (Fig. 6), which indicated different reponses of the $P p d-H 1$ gene to different environmental conditions. Although there are a few studies reported the association of the $P p d-H 1$ allele with late flowering habits (Bustos-Korts et al. 2019, Merchuk-Ovnat et al. 2018, Ponce-Molina et al. 2012, Saade et al. 2016), the underlying mechanism that caused such delay in flowering time in short-day conditions is still unclear. Borràs-Gelonch et al. (2011), Slafer and Rawson (1996) suggested that the photoperiod response of the $P p d-H 1$ gene might also relate to temperature.

Several stable regions detected by GWAS only showed significant association with flowering time in certain trials. For example, the significant QTN at the PFT1 gene region (D5H430868101_AG) only showed association with flowering time in the Esperance and Corrigin trials in 2018 (Table 1). Although the association of the PFT1 gene with flowering time in barley is still unclear, studies in Arabidopsis suggested that the PFT1 gene plays an essential role in response to light conditions (Cerdán and Chory 2003, Klose et al. 2012). In addition, the significant QTN D2H638903073_TG associated with vernalisation response were only detected using the variation in flowering time between two trials (Table 2).

\section{The barley pan-genome reveals a new mutation in the CENTRORADIALIS gene region}

Using the combination of GWAS results, high-quality SNPs from previous studies and the pangenome sequences (Hill et al. 2019a, Hill et al. 2019b, Jayakodi et al. 2020), we were able to determine a specific mutation in the $C E N$ gene region. Our result suggested that plants carrying a C-to-A SNP in the last exon of the CEN gene, which is inherited from cv. GrangeR, showed a delayed flowering habit compared to plants carrying the alleles from cvs. Compass, La Trobe and Lockyer. A previous study by Comadran et al. (2012) reported that the C-to-A SNP caused a change from Proline to Alanine in the translated protein and resulted in a delay in flowering time. Data obtained from different sowing times, various growing locations, vernalisation treatment and extended photoperiod trials confirmed that the impacts of CEN gene on flowering time were not affected from environmental conditions (Fig. 4 and Table S6). 


\section{Semi-dwarf genes GA20ox2 and DEP1 are associated with flowering time}

The association of the semi-dwarf genes, GA20ox2 and DEP1, with flowering enabled the utilisation of these genes in designing barley varieties with desired flowering time and height. Previous studies showed that the mutations in the GA20ox2 region caused shorter plant height and delayed flowering time (Jia et al. 2009, Laurie et al. 1993, Xu et al. 2017). Although many studies described the impact of the mutation in the DEP1 gene (or the ari-e gene) with plant height, salinity tolerance, and grain length (Jia et al. 2016, Watt et al. 2020, Wendt et al. 2016), its association with flowering time has not yet been fully understood. Since the ari-e gene (DEP1 mutant) was widely used for the breeding of many successful Australian barley cultivars, including cvs. Hindmarsh and La Trobe, understanding its impact on flowering time might provide better knowledge for breeding new cultivars with better adaptation to Australian growing conditions. It is possible that the combination of the GA20ox2 mutations with other alleles associated with earliness, such as the CEN allele from Compass/LaTrobe/Lockyer, might result in a shorter plant with a more balancing flowering time.

\section{Declarations}

\section{Acknowledgments}

VHD was funded by Murdoch University with the International Tuition Fee Scholarship (ITFS) and Murdoch Strategic Scholarship (MSS).

The authors thank Mrs. Sharon Westcott for providing additional material for KASP genotyping, Mrs. Jenifer Bussanich and Ms. Diem Ly for providing supports in phenotyping and genetic material collection.

\section{Conflict of Interests}

The authors declare that they have no conflict of interest.

\section{Compliance with ethics requirement}

This article does not contain any studies with human or animal subjects.

\section{Author contribution}

$\mathrm{CL}$ and $\mathrm{CBH}$ conceptualised the project. VHD and $\mathrm{XZ}$ contributed to genetic material extraction and genotyping. VHD, TTA, LM contributed to field phenotyping. VHD and CBH contributed to data analysis, 
interpretation and wrote the original paper. $\mathrm{CL}$ and $\mathrm{CBH}$ reviewed and edited the manuscript. All authors read and approved the final manuscript.

\section{Data availability statements}

The datasets generated during and/or analysed during the current study are available from the corresponding author on reasonable request.

\section{References}

1. Acquaah G (2012) Principles of plant genetics and breeding, 2nd illustrated edn. Wiley, Germany

2. Akbari M, Wenzl P, Caig V, Carling J, Xia L, Yang S, Uszynski G, Mohler V, Lehmensiek A, Kuchel H (2006) Diversity arrays technology (DArT) for high-throughput profiling of the hexaploid wheat genome. Theor Appl Genet 113:1409-1420

3. Alexander DH, Novembre J, Lange K (2009) Fast model-based estimation of ancestry in unrelated individuals. Genome Res

4. Alqudah AM, Schnurbusch T (2014) Awn primordium to tipping is the most decisive developmental phase for spikelet survival in barley. Funct Plant Biol 41:424-436

5. Alqudah AM, Sharma R, Pasam RK, Graner A, Kilian B, Schnurbusch T (2014) Genetic dissection of photoperiod response based on GWAS of pre-anthesis phase duration in spring barley. PLoS One 9:e113120

6. Altschul SF, Gish W, Miller W, Myers EW, Lipman DJ (1990) Basic local alignment search tool. J Mol Biol 215:403-410

7. Anderson W, Hamza M, Sharma D, D'Antuono M, Hoyle F, Hill N, Shackley B, Amjad M, ZaicouKunesch C (2005) The role of management in yield improvement of the wheat crop - a review with special emphasis on Western Australia. Aust J Agric Res 56:1137-1149

8. Andres F, Coupland G (2012) The genetic basis of flowering responses to seasonal cues. Nature Reviews Genetics 13:627-639

9. Barrett JC, Fry B, Maller J, Daly MJ (2004) Haploview: analysis and visualization of LD and haplotype maps. Bioinformatics 21:263-265

10. Borràs-Gelonch G, Denti M, B Thomas WT, Romagosa I (2011) Genetic control of pre-heading phases in the Steptoe $\times$ Morex barley population under different conditions of photoperiod and temperature. Euphytica 183:303-321

11. Bradbury PJ, Zhang Z, Kroon DE, Casstevens TM, Ramdoss Y, Buckler ES (2007) TASSEL: software for association mapping of complex traits in diverse samples. Bioinformatics 23:2633-2635

12. Browning BL, Zhou Y, Browning SR (2018) A one-penny imputed genome from next-generation reference panels. The American Journal of Human Genetics 103:338-348 
13. Bustos-Korts D, Dawson IK, Russell J, Tondelli A, Guerra D, Ferrandi C, Strozzi F, Nicolazzi EL, MolnarLang M, Ozkan H (2019) Exome sequences and multi-environment field trials elucidate the genetic basis of adaptation in barley. The Plant Journal 99:1172-1191

14. Cerdán PD, Chory J (2003) Regulation of flowering time by light quality. Nature 423:881-885

15. Cockram J, Jones H, Leigh FJ, O'Sullivan D, Powell W, Laurie DA, Greenland AJ (2007) Control of flowering time in temperate cereals: genes, domestication, and sustainable productivity. J Exp Bot 58:1231-1244

16. Colasanti J, Coneva V (2009) Mechanisms of floral induction in grasses: something borrowed, something new. Plant Physiol 149:56-62

17. Comadran J, Kilian B, Russell J, Ramsay L, Stein N, Ganal M, Shaw P, Bayer M, Thomas W, Marshall D (2012) Natural variation in a homolog of Antirrhinum CENTRORADIALIS contributed to spring growth habit and environmental adaptation in cultivated barley. Nat Genet 44:1388-1392

18. Coventry SJ, Barr AR, Eglinton JK, McDonald GK (2003) The determinants and genome locations influencing grain weigth and size in barley. Aust J Agric Res 54:1103

19. Cuesta-Marcos A, Casas AM, Hayes PM, Gracia MP, Lasa JM, Ciudad F, Codesal P, Molina-Cano JL, Igartua E (2009) Yield QTL affected by heading date in Mediterranean grown barley. Plant Breeding 128:46-53

20. Dang VH, Hill CB, Zhang X-Q, Angessa TT, McFawn L-A, Li C (2020) Genetic dissection of the interactions between semi-dwarfing genes $s d w 1$ and ari-e and their effects on agronomic traits in a barley MAGIC population. Mol Breed 40:1-14

21. Edgar RC (2004) MUSCLE: multiple sequence alignment with high accuracy and high throughput. Nucleic Acids Res 32:1792-1797

22. Fjellheim S, Boden S, Trevaskis B (2014) The role of seasonal flowering responses in adaptation of grasses to temperate climates. Frontiers in Plant Science 5:431

23. Francis RM (2017) pophelper: an R package and web app to analyse and visualize population structure. Molecular Ecology Resources 17:27-32

24. Friedt W, Horsley RD, Harvey BL, Poulsen DM, Lance R, Ceccarelli S, Grando S, Capettini F (2011) Barley breeding history, progress, objectives, and technology. Barley: Production, Improvement, and Uses:160-220

25. Gupta PK, Kulwal PL, Jaiswal V (2014) Association mapping in crop plants: opportunities and challenges. Adv Genet 85:109-147

26. Hill CB, Angessa TT, McFawn LA, Wong D, Tibbits J, Zhang XQ, Forrest K, Moody D, Telfer P, Westcott $S$ (2019a) Hybridisation-based target enrichment of phenology genes to dissect the genetic basis of yield and adaptation in barley. Plant Biotechnol J 17:932-944

27. Hill CB, Angessa TT, Zhang XQ, Chen K, Zhou G, Tan C, Wang P, Westcott S, Li C (2021) A global barley panel revealing genomic signatures of breeding in modern Australian cultivars. The Plant Journal 106:419-434 
28. Hill CB, Wong D, Tibbits J, Forrest K, Hayden M, Zhang X-Q, Westcott S, Angessa TT, Li C (2019b) Targeted enrichment by solution-based hybrid capture to identify genetic sequence variants in barley. Scientific Data 6:1-8

29. Jakobsson M, Rosenberg NA (2007) CLUMPP: a cluster matching and permutation program for dealing with label switching and multimodality in analysis of population structure. Bioinformatics 23:1801-1806

30. Jayakodi M, Padmarasu S, Haberer G, Bonthala VS, Gundlach H, Monat C, Lux T, Kamal N, Lang D, Himmelbach A (2020) The barley pan-genome reveals the hidden legacy of mutation breeding. Nature 588:284-289

31. Jia Q, Tan C, Wang J, Zhang X-Q, Zhu J, Luo H, Yang J, Westcott S, Broughton S, Moody D (2016) Marker development using SLAF-seq and whole-genome shotgun strategy to fine-map the semidwarf gene ari-e in barley. BMC Genomics 17:911

32. Jia Q, Zhang J, Westcott S, Zhang X-Q, Bellgard M, Lance R, Li C (2009) GA-20 oxidase as a candidate for the semidwarf gene sdw1/denso in barley. Functional \& Integrative Genomics 9:255262

33. Klose C, Büche C, Fernandez AP, Schäfer E, Zwick E, Kretsch T (2012) The mediator complex subunit PFT1 interferes with COP1 and HY5 in the regulation of Arabidopsis light signaling. Plant Physiol 160:289-307

34. Krzywinski M, Schein J, Birol I, Connors J, Gascoyne R, Horsman D, Jones SJ, Marra MA (2009) Circos: an information aesthetic for comparative genomics. Genome Res 19:1639-1645

35. Laurie D, Pratchett N, Romero C, Simpson E, Snape J (1993) Assignment of the denso dwarfing gene to the long arm of chromosome $3(3 \mathrm{H})$ of barley by use of RFLP markers. Plant Breeding 111:198203

36. Liu K, Harrison MT, Hunt J, Angessa TT, Meinke H, Li C, Tian X, Zhou M (2020) Identifying optimal sowing and flowering periods for barley in Australia: A modelling approach. Agricultural and Forest Meteorology 282:107871

37. Mascher M, Gundlach H, Himmelbach A, Beier S, Twardziok SO, Wicker T, Radchuk V, Dockter C, Hedley PE, Russell J (2017) A chromosome conformation capture ordered sequence of the barley genome. Nature 544:427

38. Maurer A, Draba V, Jiang Y, Schnaithmann F, Sharma R, Schumann E, Kilian B, Reif JC, Pillen K (2015) Modelling the genetic architecture of flowering time control in barley through nested association mapping. BMC Genomics 16:290

39. Merchuk-Ovnat L, Silberman R, Laiba E, Maurer A, Pillen K, Faigenboim A, Fridman E (2018) Genome scan identifies flowering-independent effects of barley HsDry2. 2 locus on yield traits under water deficit. J Exp Bot 69:1765-1779

40. Myles S, Peiffer J, Brown PJ, Ersoz ES, Zhang Z, Costich DE, Buckler ES (2009) Association mapping: critical considerations shift from genotyping to experimental design. The Plant Cell 21:2194-2202 
41. Ponce-Molina LJ, María Casas A, Pilar Gracia M, Silvar C, Mansour E, Thomas WB, Schweizer G, Herz M, Igartua E (2012) Quantitative trait loci and candidate loci for heading date in a large population of a wide barley cross. Crop Sci 52:2469-2480

42. Purcell S, Neale B, Todd-Brown K, Thomas L, Ferreira MA, Bender D, Maller J, Sklar P, De Bakker PI, Daly MJ (2007) PLINK: A tool set for whole-genome association and population-based linkage analyses. The American Journal of Human Genetics 81:559-575

43. R Core Team (2013) R: A language and environment for statistical computing

44. Rambaut A (2012) FigTree v1. 4.

45. Rana MR, Karim MM, Hassan MJ, Hossain MA, Haque MA (2017) Grain filling patterns of barley as affected by high temperature stress. Journal of the Bangladesh Agricultural University 15:174-181

46. Rollins JA, Drosse B, Mulki M, Grando S, Baum M, Singh M, Ceccarelli S, von Korff M (2013) Variation at the vernalisation genes $\mathrm{V} r n-H 1$ and $\mathrm{V} r n-H 2$ determines growth and yield stability in barley (Hordeum vulgare) grown under dryland conditions in Syria. Theor Appl Genet 126:2803-2824

47. Saade S, Maurer A, Shahid M, Oakey H, Schmöckel SM, Negrão S, Pillen K, Tester M (2016) Yieldrelated salinity tolerance traits identified in a nested association mapping (NAM) population of wild barley. Scientific Reports 6:1-9

48. Samarah NH (2005) Effects of drought stress on growth and yield of barley. Agronomy for sustainable development 25:145-149

49. Sasani S, Hemming MN, Oliver SN, Greenup A, Tavakkol-Afshari R, Mahfoozi S, Poustini K, Sharifi HR, Dennis ES, Peacock WJ (2009) The influence of vernalization and daylength on expression of flowering-time genes in the shoot apex and leaves of barley (Hordeum vulgare). J Exp Bot 60:21692178

50. Savin R, Nicolas ME (1999) Effects of timing of heat stress and drought on growth and quality of barley grains. Aust J Agric Res 50:357-364

51. Slafer GA, Rawson H (1996) Responses to photoperiod change with phenophase and temperature during wheat development. Field Crops Res 46:1-13

52. Turner A, Beales J, Faure S, Dunford RP, Laurie DA (2005) The pseudo-response regulator Ppd-H1 provides adaptation to photoperiod in barley. Science 310:1031-1034

53. Watt C, Zhou G, Angessa TT, Moody D, Li C (2020) A novel polymorphism in the $5^{\prime}$ UTR of HVDEP1 is associated with grain length and 1000-grain weight in barley (Hordeum vulgare). Crop and Pasture Science 71:752-759

54. Wendt T, Holme I, Dockter C, Preuß A, Thomas W, Druka A, Waugh R, Hansson M, Braumann I (2016) HvDep 1 is a positive regulator of culm elongation and grain size in barley and impacts yield in an environment-dependent manner. PLoS One 11:e0168924

55. Wiegmann M, Maurer A, Pham A, March TJ, Al-Abdallat A, Thomas WT, Bull HJ, Shahid M, Eglinton J, Baum M (2019) Barley yield formation under abiotic stress depends on the interplay between flowering time genes and environmental cues. Scientific Reports 9:1-16 
56. Xu Y, Jia Q, Zhou G, Zhang X-Q, Angessa T, Broughton S, Yan G, Zhang W, Li C (2017) Characterization of the $s d w 1$ semi-dwarf gene in barley. BMC Plant Biol 17:11

57. Zhang Y-W, Tamba CL, Wen Y-J, Li P, Ren W-L, Ni Y-L, Gao J, Zhang Y-M (2020) mrMLM v4. 0.2: An R platform for multi-locus genome-wide association studies. Genomics, Proteomics \& Bioinformatics 18:481-487

\section{Figures}
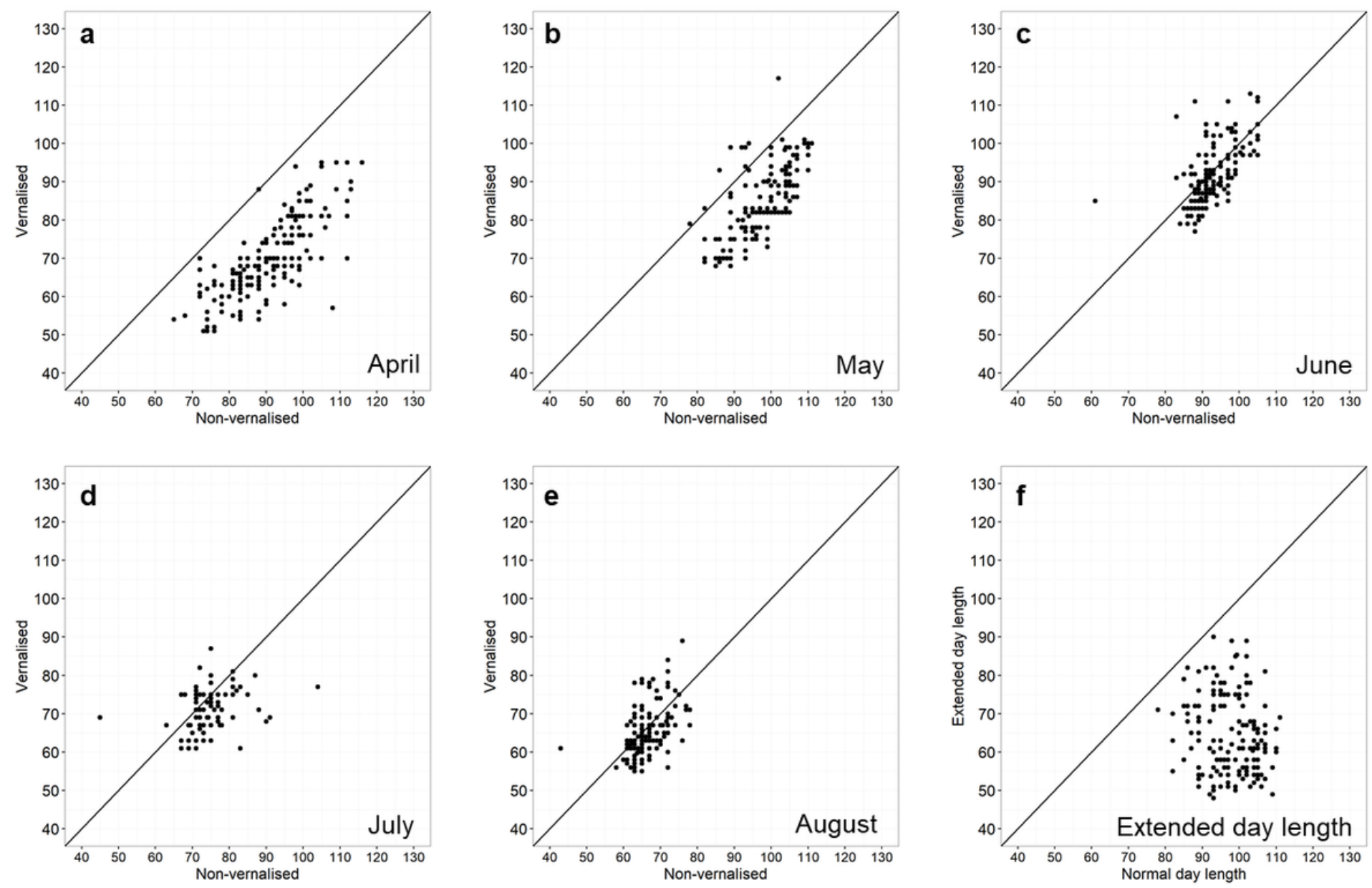

\section{Figure 1}

Scatter plot comparing flowering time between vernalised, extended photoperiod and normal conditions. Each box represents a different trial conducted in Perth in 2019 with sowing time in (a) April, (b) May, (c) June, (d) July and (e) August, and comparing (f) extended and normal photoperiod. Dots depicted the date to awn appearance (Z49) of individual plants 
a

$\square \begin{aligned} & \text { Cluster1 } \\ & \text { Cluster2 } \\ & \text { Cluster3 }\end{aligned}-\begin{aligned} & \text { Cluster4 } \\ & \text { Cluster5 } \\ & \text { Cluster6 }\end{aligned}-\begin{aligned} & \text { Cluster7 } \\ & \text { Cluster8 } \\ & \text { Cluster9 }\end{aligned} \square \begin{aligned} & \text { Cluster10 } \\ & \text { Cluster11 } \\ & \text { Cluster12 }\end{aligned}$
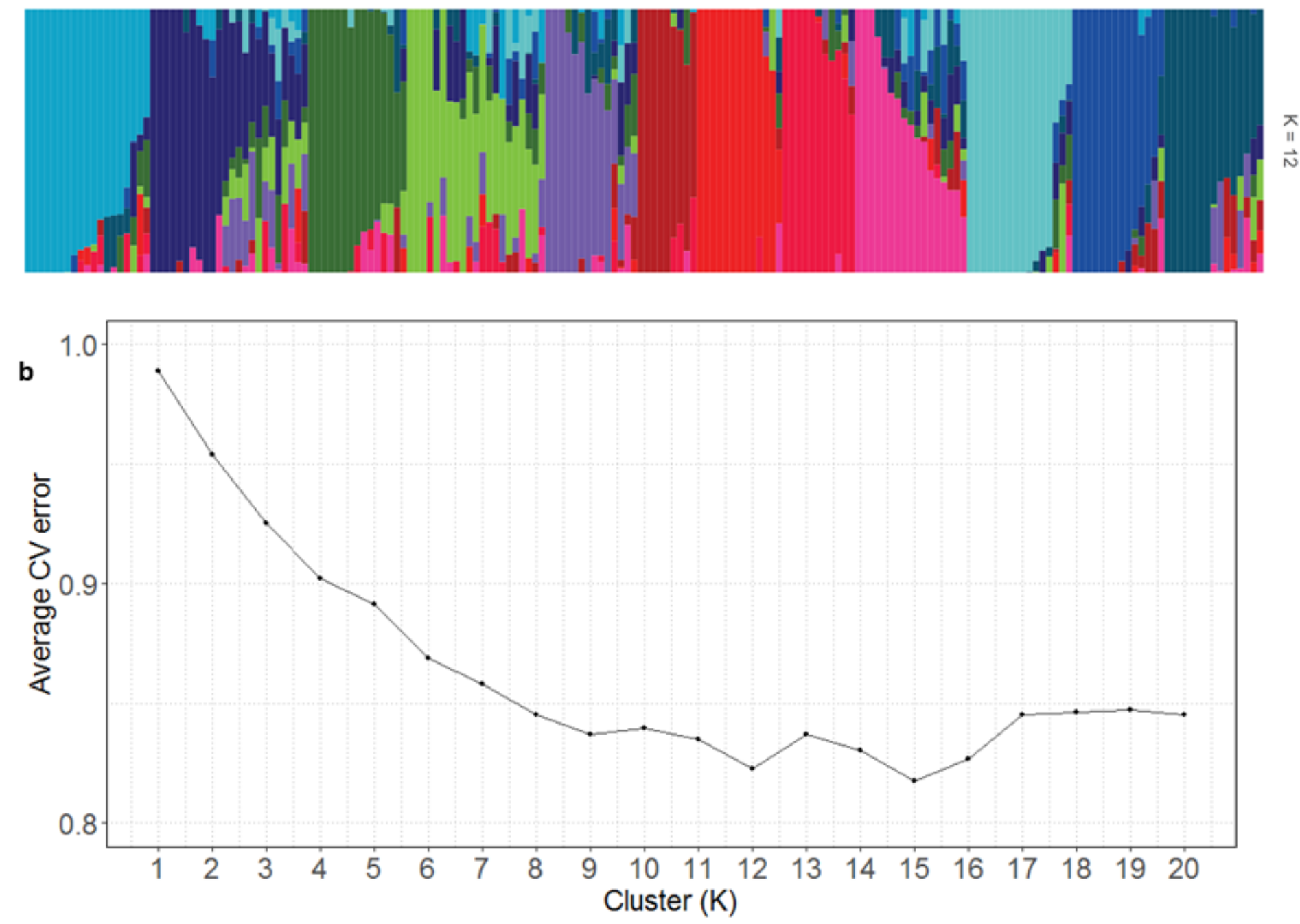

Figure 2

Population structure analysis result. (a) Ancestry plot of the population structure data from Admixture 1.3.0 12 clusters $(K=12)$ and (b) average cross-validation error of different $K$ values from 1 to 20 from population structure analysis using Admixture 1.3.0 


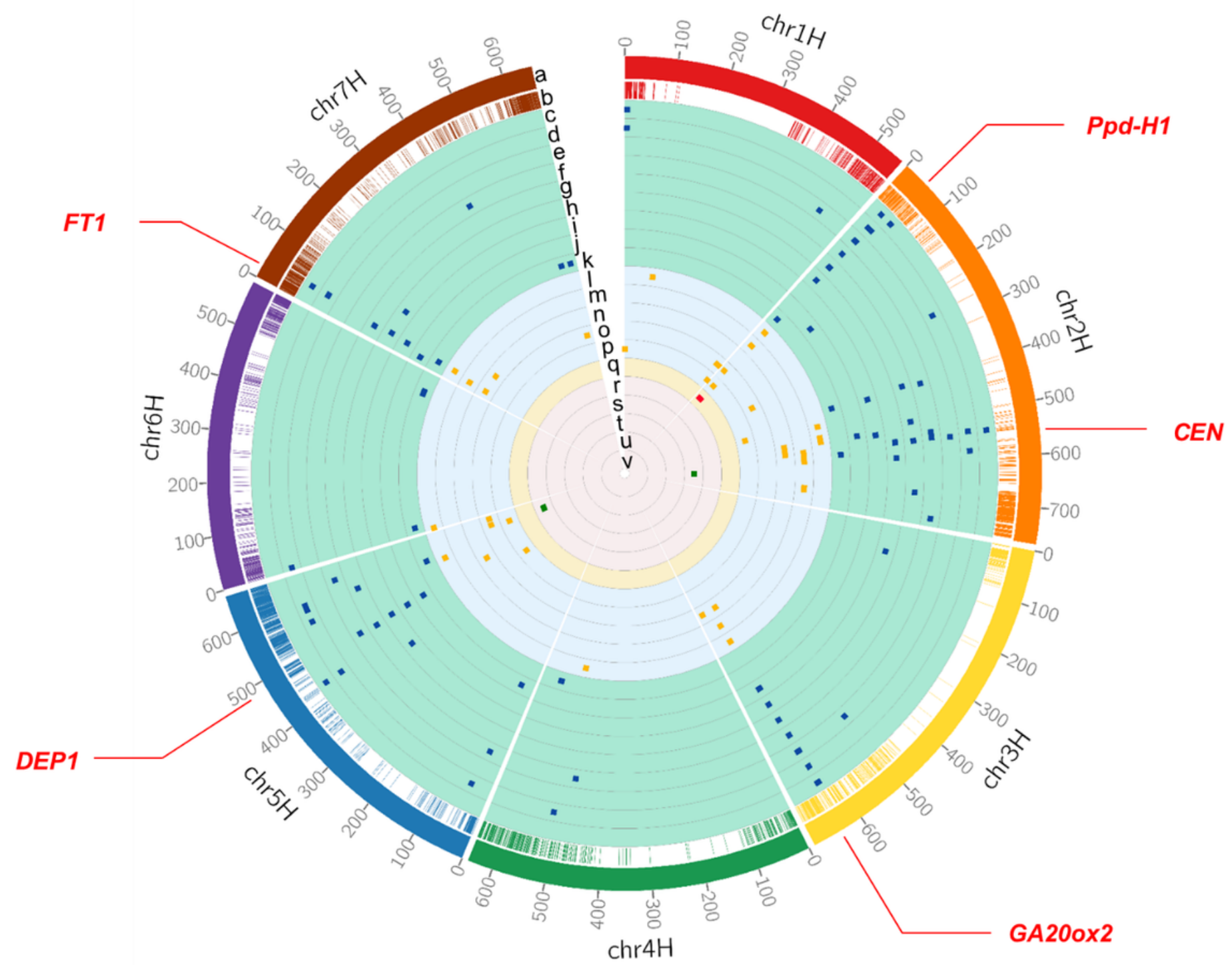

\section{Figure 3}

Genome-wide distribution of significant QTNs detected by GWAS. (a) The outermost ring with the scale represents the 7 barley chromosomes. (b) The colour lines in the inside ring represents the marker positions. The blue scatters represent the positions of significant QTNs in normal conditions, with each ring represent different trials conducted in (c) Corrigin 2018, (d) Esperance 2018, (e) Perth 2017, (f) Perth 2018, different sowing times in Perth in (g) April, (h) May, (i) June, (j) July, (k) August in 2019, respectively. The yellow scatters represent the positions of significant QTNs in vernalised trials, with each ring represent vernalised trials with different sowing times in Perth in (I) April, (m) May, (n) June, (o) July, (p) August in 2019, respectively. (q) The red scatters and yellow ring represent the positions of significant QTNs in extended photoperiod trial. The green scatters represent the positions of significant QTNs in vernalised/non-vernalised comparison, with each ring represent the vernalised/non-vernalised comparison for different sowing times in (r) April, (s) May, (t) June, (u) July, (v) August in 2019, respectively 

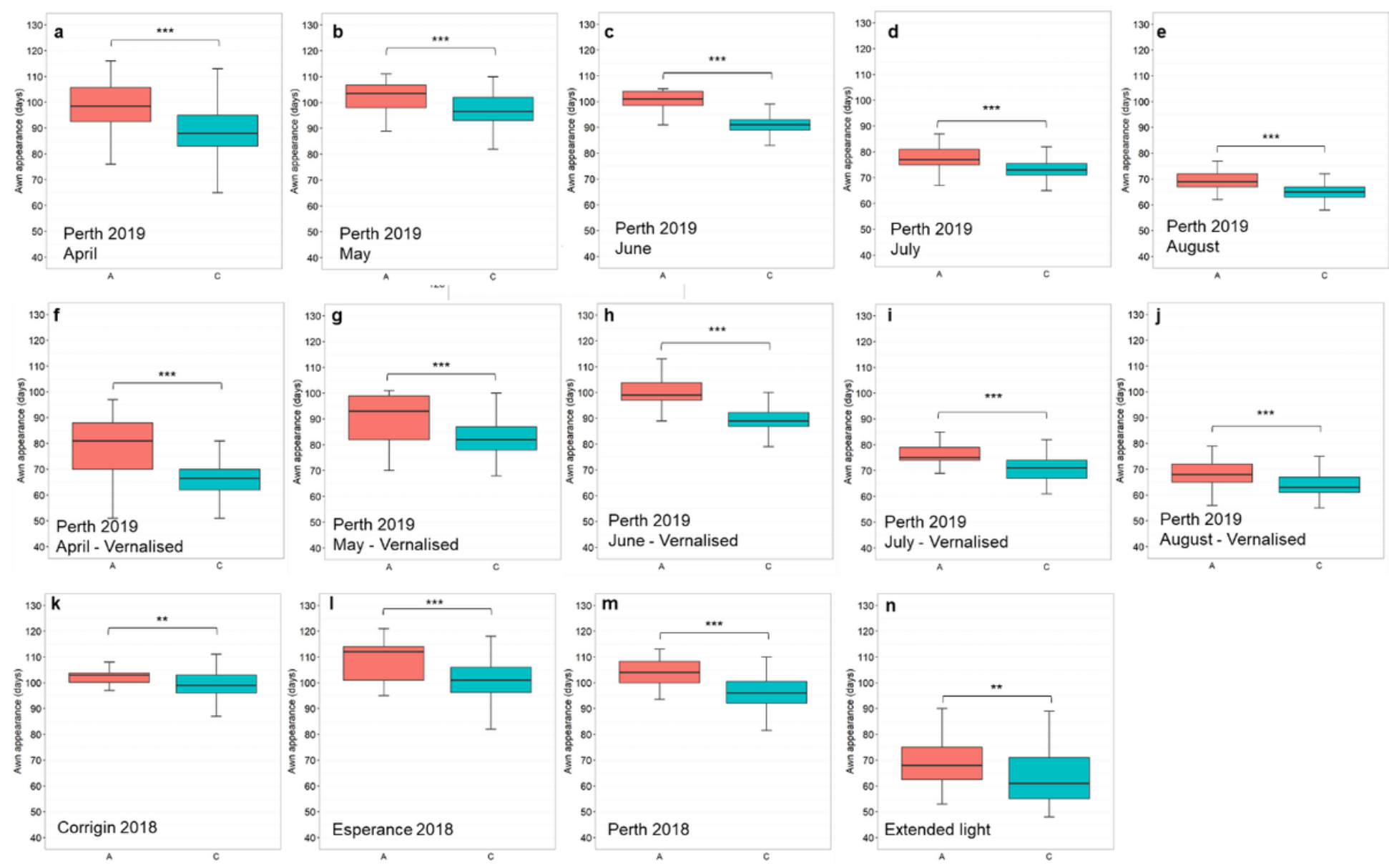

\section{Figure 4}

Boxplots for flowering time of different genotypes of the D2H519658782_AC QTN in different trials. (a-e) Non-vernalised trials with different sowing times from April to August in Perth 2019. (f-j) Trials with vernalisation sown at different times from April to August in Perth 2019. (k-m) Trials at different locations in Corrigin, Esperance and Perth 2018. (n) Extended photoperiod trial. The population was divided into two groups in each trial according to allele types. The $\mathrm{X}$-axis represents the two alleles, while the $\mathrm{Y}$-axis corresponds to flowering time (Z49). Student's t-test results shown for comparison: ** $p$-value $<0.01, * \star \star p$ value $<0.001$ 


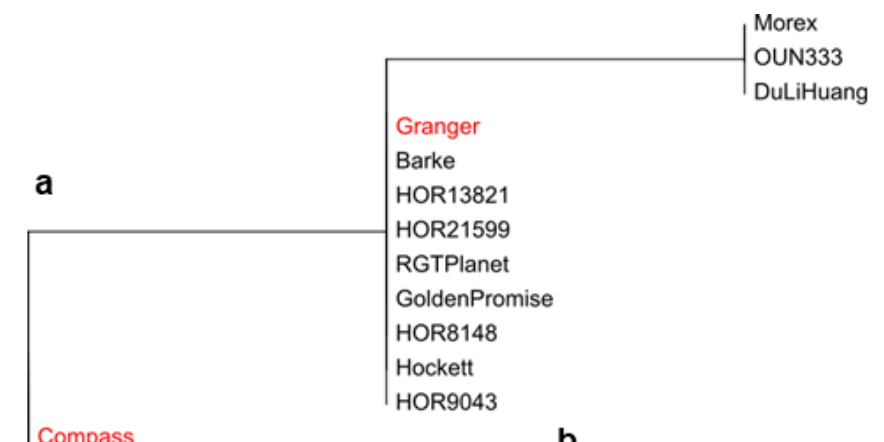

Compass

Lockyer

FT11

Akashinriki

HOR13942

HOR3081

HOR7552

Igri

Chiba

La Trobe

HOR3365 b

Igri

Barke

RGT Planet

Golden Promise

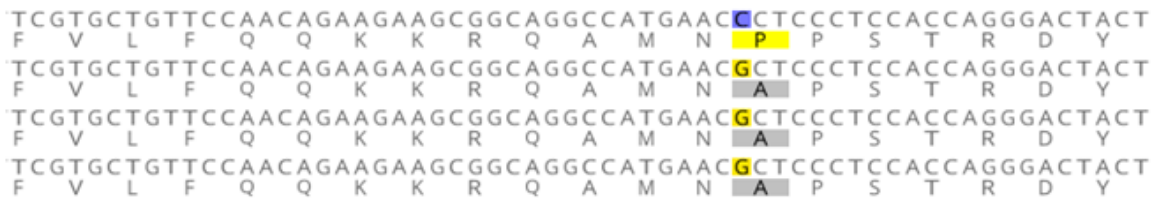

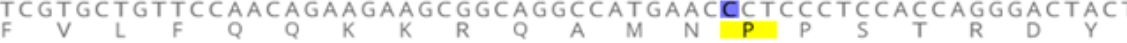

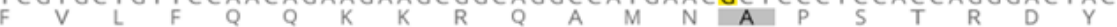
TCGTGCTGTTCCAACAGAAGAAGCGGCAGGCCATGAACGCTCCCTCCACCAGGGACTACT $V$ G

\section{Figure 5}

Sequence analysis of four parental cultivars Compass, GrangeR, La Trobe and Lockyer with 20 barley accessions from the pan-genome dataset. (a) Phylogenetic tree based on 13 genetic variants in the CEN gene region. (b) A C-to-G SNP caused an amino acid change from Proline to Alanine in cvs. Barke, RGT Planet, and Golden Promise
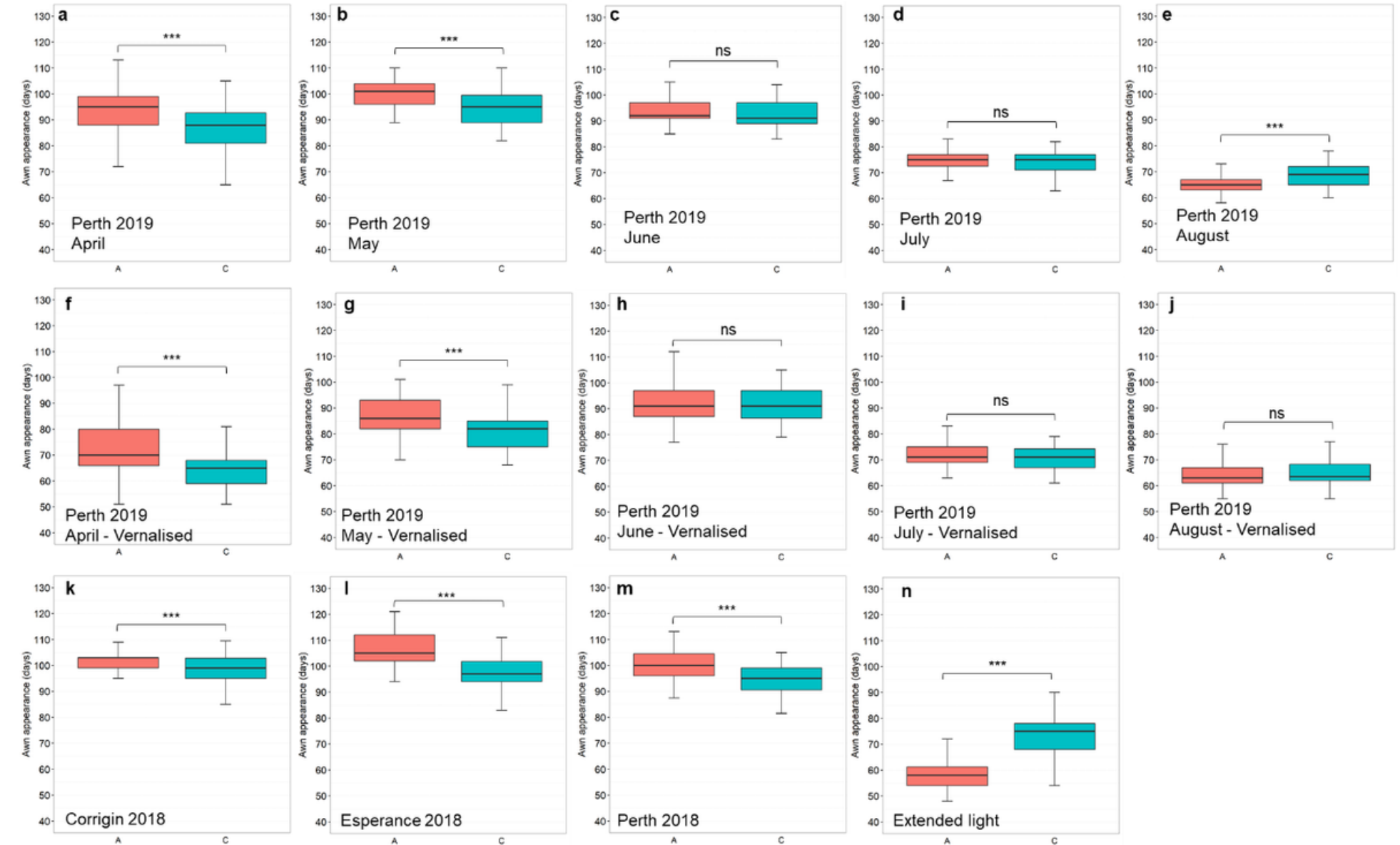


\section{Figure 6}

Boxplots for flowering time of different genotypes of the D2H29454480_AC QTN in different trials. (a-e) Non-vernalisation trials with different sowing times from April to August in Perth 2019. (f-j) Trials with vernalisation sown in different times from April to August in Perth 2019. (k-m) Trials at different locations in Corrigin, Esperance and Perth 2018. (n) Extended photoperiod trial. The population was divided into two groups in each trial according to allele types. The $\mathrm{X}$-axis represents the two alleles, while the $\mathrm{Y}$-axis corresponds to flowering time (Z49). Student's t-test results shown for comparison: ns: not significant at $p$-value $=0.05, * \star \star p$-value $<0.001$

\section{Supplementary Files}

This is a list of supplementary files associated with this preprint. Click to download.

- Supplementarymaterials.pdf 